\title{
TEAMWORK TRAINING AS A MEANS OF MASTERING MORE EQUITABLE, DIVERSE, AND INCLUSIVE PRACTICES IN ENGINEERING CURRICULA
}

\author{
Richard R. Chromik ${ }^{l}$, Diane Dechief, Denzel Guye ${ }^{I}$, Faye Siluk ${ }^{l}$, and Cathryn Somrani ${ }^{I}$ \\ Faculty of Engineering ${ }^{l}$, McGill Writing Centre ${ }^{2}$, McGill University \\ (Authors are listed alphabetically) richard.chromik@mcgill.ca
}

\begin{abstract}
Survey results and student feedback from the initial year of McGill University's E-IDEA (Engineering Inclusivity, Diversity and Equity Advancement) teamwork initiative demonstrate that undergraduate engineering students value this team-based, applied training in equity, diversity, and inclusion (EDI). The course-based training provides a critical foundation from which to build strong teamwork skills. Our findings demonstrate the benefit of initiating teamwork-integrated EDI training early in students' programs and continuing until final capstone courses.
\end{abstract}

Keywords: teamwork, equity, diversity, inclusion, projectbased learning, experiential learning.

\section{INTRODUCTION}

Working in teams is integral to both undergraduate engineering programs and industry. In order to support students during teamwork projects in courses and to prepare students for careers as professional engineers, teamwork training has become an increasingly valued component of undergraduate engineering education. In the Canadian context, recent research offers support for improving teamwork dynamics [1], sharing feedback between team members [2], using collaborative software [3], and assessing teamwork attributes [4]. However, training in equity, diversity, and inclusion (EDI) is not generally embedded as a critical component of undergraduate engineering programs. Nor has EDI education been recognized as integral to teamwork training.

Although EDI training has not been broadly included in Canadian undergraduate courses, it is very relevant to engineering education and "ethics and equity" are included in the Canadian Engineering Accreditation Board graduate attributes. Indeed, understanding and practicing equity, diversity and inclusion is a critical skillset for engineering graduates to gain in order to meet the demands of increasingly multicultural work environments [5-6]. The demographic composition of engineering programs in
Canada provides an indication of why students may benefit from learning an EDI skillset from the beginning of their programs [7]. From data from Engineers Canada, the national trend is for increasing enrollment of female students (up to $22 \%$ in 2018 compared to $17 \%$ in 2008 ). However, indigenous $(\sim 1 \%)$ and other racialized students (data unavailable) have very low representation in Canadian Engineering programs. However, engineering programs attract a fair percentage of international students $(\sim 16 \%)$, who are expected to adapt to the "unspoken rules of participation" within their programs and courses [8].

This uneven demographic composition may result in inequalities amongst team members during projects [9]. Studies of American engineering educational cultures indicate that under-represented and underserved students recognize discrimination from dominant groups but also across and within minority groups [9-10]. Misperceptions of underrepresented students' abilities - by peers during group work as well as faculty members and advisorsinfluence the retention of students from less represented groups [11-12]. For teams to function well, it is important for team members to have opportunities to develop an EDIinformed perspective. Incorporating EDI in teamwork training is particularly beneficial because engineering students are accustomed to "learning by doing". Training that supports team-based learning allows students to examine their own behaviours within their teams and throughout a term - this makes the learning personal and increases its relevance [1].

During 2019 and 2020, McGill Engineering's E-IDEA teamwork initiative introduced in-class teamwork training incorporating the practical application of equity, diversity and inclusion to augment interpersonal skills. An understanding of EDI practice is foundational to successful teamwork. Based on initial surveys and feedback that demonstrate students' recognition of the value of this approach, we suggest that undergraduate engineering programs will benefit from embedding course-based EDI learning as part of teamwork training. 


\section{CONTEXT}

\subsection{Faculty trends and project goals}

The Faculty of Engineering at McGill created the Engineering Inclusivity, Diversity and Equity Advancement (E-IDEA) initiative in 2016 to promote these principles throughout our community. The teamwork initiative, the focus of this paper, was motivated by a desire to enhance training for the graduate attributes of Ethics \& Equity and Individual and Teamwork, which prior to this initiative were addressed only at two points for most of the curriculum for our programs. Our approach was to build knowledge and discuss examples of where equity is considered in the engineering profession. Other strong goals of E-IDEA are to help diversify the profession and cultivate a culture that values engineering decisions informed by a diversity of backgrounds and opinions. Through the teamwork initiative, we wanted to provide our engineering students with the best possible understanding of equity and teamwork.

\subsection{9/2020 activities overview}

In Fall 2019, we launched the first iteration of the teamwork initiative with one designer-facilitator working with four professors to embed EDI training into their courses through team-based workshops and assignments. Each course included two to three embedded workshops. Significant feedback was gathered from students and professors via assignments and surveys. This feedback was used for programming improvements during the Winter 2020 semester.

In Winter 2020, we implemented the second iteration of the project with an expanded team of two designerfacilitators and four research assistants. Working as a larger team allowed facilitators and research assistants to critically examine our project and to practice team-building skills. The diversity of our team meant that each of us heard a variety of perspectives - from engineers and nonengineers, as well as teammates who differed by gender, nationality, ethnicity, language, culture, sexual orientation, and age - which helped us to actively engage an EDI lens.

The designer-facilitators and RAs worked with five professors to incorporate teamwork training in their courses (see Table 1).

Table 1: Partner courses for Winter 2020

\begin{tabular}{|l|l|l|}
\hline Course name & $\begin{array}{l}\text { Year of } \\
\text { Study }\end{array}$ & $\begin{array}{l}\text { Number of } \\
\text { students }\end{array}$ \\
\hline $\begin{array}{l}\text { ECSE 223 Model- } \\
\text { Based Programming }\end{array}$ & $\begin{array}{l}\text { entry level } \\
\text { U1 }\end{array}$ & 130 \\
\hline $\begin{array}{l}\text { CHEE 456 Design } \\
\text { Project I }\end{array}$ & Capstone & 33 \\
\hline $\begin{array}{l}\text { MIME 452 Process and } \\
\text { Materials Design }\end{array}$ & Capstone & 45 \\
\hline
\end{tabular}

\begin{tabular}{|l|l|l|}
\hline $\begin{array}{l}\text { MIME 559 Aluminum } \\
\text { Physical Metallurgy }\end{array}$ & U4 & 18 \\
\hline $\begin{array}{l}\text { MIME 571 Surface } \\
\text { Engineering }\end{array}$ & U4 & 18 \\
\hline
\end{tabular}

We embedded between two and five of the workshops described in Table 2 in each course. Decisions about content and scheduling were made to support course syllabi and to complement teamwork benchmarks for each project. Half of the partnering professors opted for our support in the process of creating teams with an equity-informed lens. "Foundations" workshops were facilitated during the first few weeks of class, as students began their projects. "Skill Building" workshops occurred once teams were already engaged in their work together, thus experiencing the complexity of interpersonal dynamics. This timing provided students with opportunities to immediately apply their learnings to their actual projects.

Table 2: Embedded workshops for Winter 2020

\begin{tabular}{|c|c|c|}
\hline $\begin{array}{c}\text { Workshop } \\
\text { Titles }\end{array}$ & $\begin{array}{c}\text { Teamwork Skill } \\
\text { Development }\end{array}$ & EDI concepts \\
\hline \multicolumn{3}{|c|}{ Foundations } \\
\hline $\begin{array}{l}\text { Understanding } \\
\text { yourself and } \\
\text { working with } \\
\text { different } \\
\text { personalities }\end{array}$ & $\begin{array}{l}\text { Self-awareness; } \\
\text { relating and } \\
\text { connecting; } \\
\text { observing } \\
\text { behavioural } \\
\text { patterns and } \\
\text { preferences }\end{array}$ & $\begin{array}{l}\text { Defining and } \\
\text { illustrating equity, } \\
\text { diversity, and } \\
\text { inclusion in } \\
\text { context; implicit } \\
\text { bias; power; } \\
\text { identity; micro- } \\
\text { inequities; } \\
\text { meritocracy }\end{array}$ \\
\hline $\begin{array}{l}\text { Understanding } \\
\text { yourself and } \\
\text { your team } \\
\text { through learning } \\
\text { styles }\end{array}$ & $\begin{array}{l}\text { Self-awareness; } \\
\text { relating and } \\
\text { connecting; } \\
\text { observing } \\
\text { learning-style } \\
\text { patterns and } \\
\text { preferences }\end{array}$ & $\begin{array}{l}\text { Defining and } \\
\text { illustrating equity, } \\
\text { diversity, and } \\
\text { inclusion in } \\
\text { context; ability and } \\
\text { disability; } \\
\text { meritocracy }\end{array}$ \\
\hline \multicolumn{3}{|c|}{ Skill Building } \\
\hline $\begin{array}{l}\text { Examining } \\
\text { power and } \\
\text { implicit bias in } \\
\text { team dynamics }\end{array}$ & $\begin{array}{l}\text { Understanding } \\
\text { team formation; } \\
\text { active listening }\end{array}$ & $\begin{array}{l}\text { Power dynamics; } \\
\text { stereotyping; } \\
\text { implicit bias; } \\
\text { privilege; } \\
\text { microaggressions }\end{array}$ \\
\hline $\begin{array}{l}\text { Impact of } \\
\text { structure, roles, } \\
\text { and } \\
\text { responsibilities } \\
\text { in team } \\
\text { dynamics }\end{array}$ & $\begin{array}{l}\text { Learning to } \\
\text { operate as a } \\
\text { team; } \\
\text { understanding } \\
\text { team formation }\end{array}$ & $\begin{array}{l}\text { Power; privilege; } \\
\text { prejudice; bias; } \\
\text { mitigating } \\
\text { prevalence and } \\
\text { consequence of } \\
\text { implicit bias }\end{array}$ \\
\hline $\begin{array}{l}\text { Balancing task } \\
\text { and process in } \\
\text { teamwork }\end{array}$ & $\begin{array}{l}\text { Differentiating } \\
\text { task and process; } \\
\text { active listening; } \\
\text { asking questions }\end{array}$ & $\begin{array}{l}\text { Valuing diversity; } \\
\text { mitigating } \\
\text { prevalence and } \\
\text { consequence of } \\
\text { implicit bias }\end{array}$ \\
\hline $\begin{array}{l}\text { Developing } \\
\text { intention \& }\end{array}$ & $\begin{array}{l}\text { Effective meeting } \\
\text { skills; active } \\
\text { listening; }\end{array}$ & $\begin{array}{l}\text { Power dynamics } \\
\text { and prejudice in }\end{array}$ \\
\hline
\end{tabular}




\begin{tabular}{|l|l|l|}
\hline $\begin{array}{l}\text { structure in } \\
\text { team meetings }\end{array}$ & $\begin{array}{l}\text { developing } \\
\text { shared values }\end{array}$ & $\begin{array}{l}\text { traditional team } \\
\text { roles }\end{array}$ \\
\hline $\begin{array}{l}\text { Giving and } \\
\text { receiving }\end{array}$ & Giving and & Valuing diverse \\
feedback & receiving & perspectives; \\
& feedback; & mitigating conflict \\
& building capacity & \\
& for conflict & \\
& engagement & \\
\hline
\end{tabular}

\subsection{Teamwork Initiative Approach}

Our approach embeds applied, relevant, and dynamic EDI training into course-based teamwork experiences. Students not only learn about EDI concepts, but they also experience situations where these concepts come to life and must be grappled with in team contexts. We endeavoured, as much as the scope of our involvement with each course allowed, to take participants through four stages of learning EDI: awareness, knowledge, skills, action [13]. We began with self-awareness through personality types, learning preferences, and implicit bias. We engaged in knowledge acquisition and skill building through lectures, discussions, activities, challenges and case-studies. We endeavored to inspire students to action by making the topics personal and pertinent. Our goal is for students to gain a more nuanced understanding of EDI concepts in daily life as they move through these learning experiences.

\section{DATA COLLECTION}

From the outset, we planned to gather data to gain an understanding of the initiative's impacts as well as to improve overall programming and individual workshops.

Students were surveyed about their experiences with the teamwork initiative both at the mid- and end-points of the semester. They were asked to rate their experiences with their teams as well as to ask how the teamwork initiative impacted team behavior. Students indicated which workshops impacted how they worked in their teams. There were opportunities to comment and to provide critical feedback.

It is important to note that comparing survey responses between courses has limitations due to the significant differences between the courses. The only early-year course, ECSE 223, had 130 students enrolled while the 400- and 500-level courses had enrollments as low as 18 students. In addition, in one course, students received marks for completing the surveys.

\section{RESULTS AND DISCUSSION}

Survey data from the Winter 2020 semester of the teamwork initiative demonstrates that students felt that the support offered by the teamwork initiative benefitted their teams. Additionally, EDI-focussed topics were recognized as beneficial across all courses. Student comments recommended that the teamwork initiative be implemented to support students throughout their programs of study, especially as they commence teamwork projects in earlier years and again as they complete their industry-related capstone projects.

\subsection{Teamwork initiative's impact on teams}

The final survey asked if the workshops impacted teams' behaviour with three response options: "Yes, frequently", "Sometimes", and "Not really". Student responses ranged between $71 \%$ of the class and $87 \%$ of the class selecting either "Yes" or "Sometimes".

Another question asked which topics most impacted their team behaviour (see Fig. 1). Almost all of the top responses to this question intersected with the function of increasing knowledge of self and other: learning about personality types, getting to know one another, a case study about team dysfunction, and learning about team mindset and roles were all topics highlighted as most impactful.

Clearly, individual students and team dynamics benefit from having the opportunity to build relationships. In addition to fostering a more cohesive team mindset, relationship building contributes to students feeling more comfortable asking for help and navigating the complexities of their project as a cohesive team. This is underscored by one comment from an ECSE 223 student: "I liked the team workshops, they allowed our team to bond together and break the ice. We became more comfortable asking for help after the team workshops."

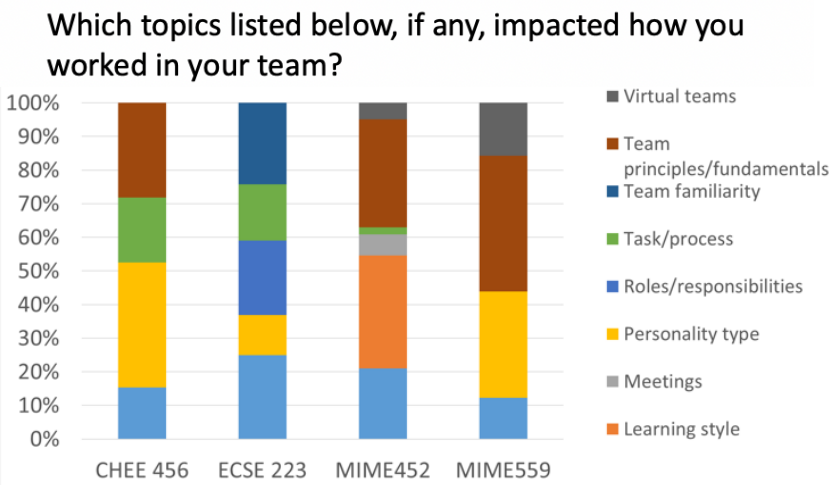

Fig. 1: How topics impact teams

\subsection{Engagement with EDI topics}

The results from the feedback surveys indicate that students gained awareness of the potential impact of implicit bias on their teamwork activities. This recognition of the presence of EDI in team processes is demonstrated by responses to the question, "Which topics impacted your teamwork?". Reflecting on implicit bias was impactful for $63 \%$ of students in a chemical engineering course, $47 \%$ and $31 \%$ in mining and materials engineering courses, and $14 \%$ in an early-year electrical and software engineering course. There are a variety of ways to interpret this response, but 
we take even the lower percentage as an indication that students are aware of and appreciate EDI as a factor involved in team dynamics.

Another possible interpretation of this finding is that the youngest cohort in the teamwork initiative may be less comfortable or engaged by EDI topics. However, Figure 2 demonstrates that ECSE 223 students found the EDI components of the teamwork initiative to be the most impactful for their teams.

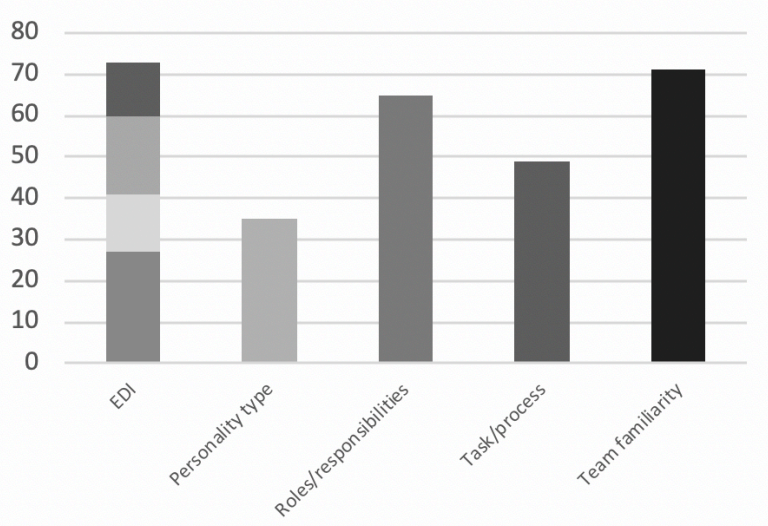

a Understanding power and privilege

a Team roles \& responsibilities

- Myth of Meritocracy (the notion that if you just work hard enough you can do anything)

1 Implicit/Unconscious bias (attitudes and beliefs about others that we absorb from our social environment)

a Getting to know one another (sharing responses to questions around your interests, what surprised you, and common challenges in teams)

a Defining equity, equality, and inclusion

घig Five personality test (gaining self awareness of preferences and tendencies)

a Balancing task vs. process

Fig. 2: How topics impact teams (ECSE 223)

\subsection{Comments on timeliness of initiative}

Student feedback suggested the need for more structured development of teamwork and EDI learning throughout undergraduate programs, with deep links to course content. As stated by one student participant, "The teamwork workshops are useful, but I hope they can be involved in the courses in the earlier years of undergraduate studies. This way, the workshop may be more helpful and make a larger influence in the future of team building." This feedback aligns with our goal of facilitating participants' growth through four stages of learning EDI
[13] by staggering workshops throughout undergraduate programs.

Having time to build awareness and develop knowledge and skills throughout their programs would provide students with increased opportunities to practice putting theoretical skills into action, thus moving towards mastery.

\subsection{Future plans}

There is substantial interest from both students and professors for course-based EDI and teamwork training and there remain numerous opportunities for growth and deeper integration of EDI training in engineering programs - especially by engaging students from their first year until their final year. This is a key focus as we plan for the 2020-2021 academic year.

Given this faculty-wide interest in applied EDI learning, we will continue collecting data to track longitudinal impact, trends and needs which emerge from both the students' and professors' perspectives.

Making clearer links between our project goals, the CEAB Graduate Attributes, and program progression may allow for deeper integration in future iterations.

Investigating differing departmental trends may offer further insights about future EDI training.

\subsection{Limitations}

As the teamwork initiative is in its early iterations, we are still working to tailor workshops for the needs and content of each course. Our long-term goal is to balance generalized and course-specific content on teamwork and EDI as we embed these learning opportunities across departments and throughout levels of study.

Additionally, the COVID-19 pandemic resulted in McGill University suspending classes beginning March 13 and then returning via remote teaching from March $30^{\text {th }}$ until the end of classes. These scheduling shifts meant that the teamwork initiative did not include specialized, embedded teamwork clinics to respond to issues or challenges faced in specific courses. As well, student teams had to complete their projects without meeting face-toface. Future iterations will include teamwork clinics and supports for online meetings.

\section{CONCLUSIONS}

Although we are in the early stages of McGill Engineering's E-IDEA teamwork initiative, survey responses suggest that incorporating EDI learning as part in-class teamwork training is of value to students.

Mid- and end of semester surveys indicate that in-class teamwork training workshops impacted how teams worked together and shows that students engaged positively with developing an EDI perspective. 
Feedback suggests that scaffolding EDI learning with teamwork training throughout undergraduate programs would increase learning. This would better distribute the four stages of learning EDI that are currently engaged by the teamwork initiative (awareness, knowledge, skills, action) [13].

Based on our initial progress with this initiative, and given the potential benefits to students during their programs and in their future careers, we recommend the approach of incorporating EDI learning as part in-class teamwork training.

\section{REFERENCES}

[1] Ostafichuk, P., Hodgson, A., Bartek, S., and Naylor, C. (2010). Teaching team dynamics: Experiences in second-year mechanical engineering design. Proceedings of the 6th International CDIO Conference, École Polytechnique, Montréal.

[2] O’Neill, Thomas and Nicoleta Maynard. (2018). How to make peer feedback in teams useful: An empirical study. Proceedings of the 2018 Canadian Engineering Education Association, CEEA.

[3] Gibbard, K., Grocull, A., Turner, A. O’Neill, T., Brennan, R., and Li, S. (2018). Assessment of individual and teamwork attributes in undergraduate engineering students. Proceedings of the 2018 Canadian Engineering Education Association, CEEA.

[4] Gidion, G., \& Buchal, R.O. (2013). Fostering teamwork skills using collaboration software in engineering design education. Proceedings of the 2013 Canadian Engineering Education Association, CEEA.

[5] Delaine, D.A., Williams, D.N., Sigamoney, R., and Tull, R.G. (2016). Global diversity and inclusion in engineering education: Developing platforms toward global alignment. International Journal of Engineering Pedagogy, 6(1), 56-71. http://dx.doi.org/10.3991/ijep.v6i1.5372

[6] Ihsen, S., and Buschmeyer, A., (2007). Acting diverse: target group orientation as key competence in engineering education. European Journal of Engineering Education, 32(6), 665-673. DOI: $10.1080 / 03043790701520610$

[7] Long, J., Apostolou, K., Mantock, M., Maidment, Y., and Ross, W. (2018). Research in an engineering technology program: Promising practices for diversity research initiatives in post-secondary education. Proceedings of the 2018 Canadian Engineering Education Association, CEEA.

[8] Zevenbergen, R. (2001) Changing context in tertiary mathematics: Implications for diversity and equity. In D. Holton, M. Artigue, U. Kirchgräber,J. Hillel, M.Niss, and A. Schoenfeld (Eds.), The Teaching and
Learning of Mathematics at University Level (pp. 1326). Springer, Dordrecht.

[9] Walden, Susan E., Deborah A. Trytten, and Randa L. Shehab (2018). Research-based Recommendations for Creating an Inclusive Culture for Diversity and Equity in Engineering Education. Proceedings of 2018 IEEE Global Engineering Education Conference (Educon) Emerging Trends and Challenges of Engineering Education,1591-1597.

[10] Rambo-Hernandez, K.E., Morris, M.L., Casper, A., Hensel, R.A., Schwartz, J.C., and Atadero, R.A. (2019). Examining the effects of equity, inclusion, and diversity activities in first-year engineering courses. Proceedings of the 126th Annual Conference \& Exposition. American Society for Engineering Education. ASEE.

[11] Kronberger, N. and I. Horwath (2013). The Ironic Costs of Performing Well: Grades Differentially Predict Male and Female Dropout From Engineering. Basic and Applied Social Psychology 35(6): 534-546.

[12] Lichtenstein, Gary, Helen L. Chen, Karl A. Smith, and Theresa A. Maldonado. (2013). Retention and Persistence of Women and Minorities Along the Engineering Pathway in the United States. Cambridge Handbook of Engineering Education Research: 311334.

[13] Hartwell, E.E., Cole, K., Donovan, S.K., Greene, R.L., Burrell Storms, S.L., and Williams, T. (2017). Breaking down silos: Teaching for equity, diversity, and inclusion across disciplines. Humboldt Journal of Social Relations, 39(39),143-162.

\section{ACKNOWLEDGEMENTS}

We are grateful to funding from ECQ: Entente Canada Quebec. We would like to acknowledge the collective efforts of our 2019-20 E-IDEA team as well as previous EDI initiatives in McGill's Faculty of Engineering for bringing this project to life. Thank you to Fabrice Labeau, Tynan Jarrett, Meryem Benslimane, and Maria OrjuelaLaverde for your foundational work on EDI topics in the faculty. Thanks to Jim Nicell for valuing and prioritizing this work in the faculty, and to Kaila Folinsbee for supporting E-IDEA's funding efforts. Thank you to our partnering professors during this pilot year of the teamwork initiative, and to all the students who learned alongside us. Your participation and feedback help us build and improve upon this program for years to come. A big thanks to our support team: Rhianne Fiolka, Hanie Kazari, and Alejandro Pérez Villaseñor, with whom we had the pleasure of experiencing EDI practices in an applied and dynamic work setting throughout this endeavour. 